\title{
Dendrosomal Curcumin Inhibits Metastatic Potential of Human SW480 Colon Cancer Cells through Down-regulation of Claudin1, Zeb1 and Hef1-1 Gene Expression
}

\author{
Mohammad Javad Dehghan Esmatabadi ${ }^{1}$, Baharak Farhangi ${ }^{1}$, Zahra Safari ${ }^{2}$, \\ Hanif Kazerooni $^{3}$, Hadi Shirzad ${ }^{4}$, Fatemeh Zolghadr ${ }^{1 *}$, Majid Sadeghizadeh ${ }^{1 *}$
}

\begin{abstract}
Colon cancer is one of the leading causes of cancer-associated death worldwide. The prognosis for advanced colorectal cancers remains dismal, mainly due to the propensity for metastatic progression. Accordingly, there is a need for effective anti-metastasis therapeutic agents. Since a great body of research has indicated anticancer effects for curcumin, we investigated the effects of dendrosomal curcumin (DNC) on cellular migration and adhesion of human SW480 cells and possible molecular mechanisms involved. Different methods were applied in this study including MTT, Scratch and adhesion assays as well as real-time PCR and transwell chamber assays. Based on the results obtained, DNC inhibits metastasis by decreasing Hef 1, Zeb 1 and Claudin 1 mRNA levels and can reduce $S W 480$ cell proliferation with $\mathrm{IC}_{50}$ values of $15.9,11.6$ and $7.64 \mu \mathrm{M}$ at 24,48 and $72 \mathrm{~h}$ posttreatment. Thus it might be considered as a safe formulation for therapeutic purpose in colorectal cancer cases.
\end{abstract}

Keywords: Colorectal cancer - dendrosomal curcumin - metastasis - cellular adhesion - human SW480 cells

Asian Pac J Cancer Prev, 16 (6), 2473-2481

\section{Introduction}

Colorectal cancer (CRCs) is the third most common cancer in men and the second in women (Ferlay et al., 2008; Ku et al., 2012). Generally, the lowest incidence rates among both men and women are reported in Africa, Central and South America, and South Central Asia (India and Pakistan) (Ferlay et al., 2008; Ku et al., 2012). The prognosis for advanced CRCs remains dismal, mainly due to the propensity for metastatic progression (Gulhati et al., 2011). In the initial step of cancer metastasis, tumor cells sometimes undergo epithelial-mesenchymal transition (EMT), which requires the disruption of cell-cell adhesions (Hynes, 2002; Meng and Takeichi, 2009). In many cases, metastasis may occur as a result of dysregulation in cell adhesions molecules or signaling cascades proteins involved in cell adhesion such as Hef 1 (Li et al., 2011), Zeb 1 (Amar et al., 2011) and Claudin 1(Cld 1) (Nobutomo et al., 2001), that in previous study, were suggested to be associated with cellular migration in colon cancer. Accordingly, there is a need for nontoxic therapeutic agents which are easy and effective to use for cancer prevention and treatment. About $80 \%$ of all anticancer drugs today are somehow composed from natural products (Kuo et al., 1996; Zhang et al., 2012). One of the most important natural compounds is curcumin (diferuloylmethane), the main component of turmeric (Sporn, 1997; Xia et al., 2014). It has been used as a spice and a traditional medicine for many centuries in India and other Asian countries (Ammon and Wahl, 1991; Kuo et al., 1996). Chemo-preventive and therapeutic features of curcumin including anti-cancer, anti-inflammatory and antioxidant activities were previously confirmed in in vitro and in vivo models (Khor et al., 2006). The most important property of curcumin was suggested to be its selective role in targeting cancer cells against normal cells(Ravindran et al., 2009; Das et al., 2010). However, low water solubility and poor uptake remain major obstacles, limiting the use of curcumin as an anticancer treatment agent (Anand et al., 2007). Recently, scientists have revealed several strategies, such as loading synthetic analogs from turmeric, liposomal formulations and nanoparticles of curcumin, to overcome the mentioned problems (Anand et al., 2008; Ferrari et al., 2011; Kushwaha et al., 2012; Orr et al., 2012). Dendrosome was introduced as a delivery system in the authors' research group. This carrier possess valuable advantages over other carriers, which include ease of synthesis, stability, nontoxicity, inexpensiveness,

${ }^{1}$ Department of Genetics, Faculty of Biological Sciences, ${ }^{4}$ Department of Medical Genetics, Faculty of Medical Sciences, Tarbiat Modares University, ${ }^{2}$ Genetics Group, Cancer Research Center, Cancer Institute of Iran, Tehran University of Medical Sciences, ${ }^{3}$ Chemical Engineering Faculty, Amirkabir University of Technology (Tehran Polytechnic), Tehran, Iran *For correspondence: sadeghma@modares.ac.ir,zolghadr@modares.ac.ir 
biodegradability, neutrality, spherical structure, capability of easily delivering drugs and being extremely convenient to handle and use (Sarbolouki et al., 2000; Sadeghizadeh et al., 2008; Babaei et al., 2012). Accordingly, in the present study, in continuation of our previous works, a 400th generation Dendrosome (Den400) was used as a carrier for curcumin (Paleos, 2013). There are few studies reporting the effect of curcumin on cancer cell metastasis, adhesion to extracellular matrix (Bharat et al., 2005; Aggarwal et al., 2006; Hong et al., 2006) and there is however, no available information to address the effects of curcumin on migration and invasion of SW480 cells, a cellular model of metastatic colorectal cancer (Trainer et al., 1988). Moreover, the impact of curcumin on the expression of Zeb 1, Claudin 1 and Hef 1, molecules involved in cell adhesion, has not yet been investigated. A better understanding of the mechanisms of drug would enhance the therapeutic potential of curcumin either alone or in combination with other anticancer. Therefore, the purpose of this study is to evaluate the effects of dendrosomal curcumin on cell migration and adhesion to extracellular matrix of SW480 cells and possible molecular mechanisms involved. The results obtained showed that dendrosomal curcumin concentration dependently inhibits the migration and adhesion to ECM in SW480 cells. This inhibitory activity was mediated by downregulation of Zeb 1, Claudin 1 and Hef 1 genes in SW480 cells. Altogether, our findings suggest that dendrosomal curcumin might have an anti-metastatic effect by decreasing invasiveness of cancer cells and thus, could be assumed as a powerful candidate for developing preventive agents for tumor metastasis.

\section{Materials and Methods}

\section{Cell lines and reagents}

The human colon cancer SW480 cell line was obtained from Pasteur Institute of Iran (Tehran, Iran) and cultured in RPMI 1640 medium (Invitrogen) supplemented with $10 \%$ fetal bovine serum (Invitrogen) and $1 \%$ penicillinstreptomycin (Gibco, Scotland) in $5 \% \mathrm{CO}_{2}$ at $37^{\circ} \mathrm{C}$. Curcumin was purchased from Merck KGaA (Darmstadt, Germany) with purity of $95 \%$. Dendrosome nanoparticle specified Den 400, a nonionic biodegradable denderic glycol ester (MW: 590 Da, HLB: 12.5 Mh/M, hydroxyl value: $95 \mathrm{mg} \mathrm{KOH} / \mathrm{g}$ and acid value: $\mathrm{mg} \mathrm{KOH} / \mathrm{g}$ ) was a gift from Institute of Biochemistry and Biophysics, University of Tehran, Iran. Dendrosome 'Synthesis protocol has previously been described (Mirgani et al., 2014).

\section{Dendrosomal curcumin (DNC) preparation}

For DNC preparation, we used an optimized protocol of our lab (Mirgani et al., 2014). Briefly, different weight/ weight ratios of Dendrosome/curcumin ranging from 50:1 to $10: 1$ were examined before settling a suitable ratio of 25:1. Curcumin was dissolved in various amounts of Dendrosome and checked for absorbance spectra by UV spectrophotometery (TECAN, Switzerland). Then, the appropriate mixture of Dendrosome and curcumin was evaluated for excitation/emission value in comparison with curcumin dissolved in PBS and 1\% methanol as control sample. The loading of Dendrosome nanocarriers with curcumin molecules was performed using MaLing Gou et al protocol (Gou et al., 2011). Briefly, curcumin and Dendrosome were co-dissolved in $5 \mathrm{~mL}$ of acetone; this solution was added into $5 \mathrm{~mL}$ of PBS while stirring constantly. Then, the acetone was evaporated in rotary evaporator. The curcumin/Dendrosome micelle solution was sterilized using a $0.22 \mu \mathrm{m}$ syringe filter (Millex-LG, Millipore Co., USA). Finally, the prepared DNC was stored in $4^{\circ} \mathrm{C}$ in a light protected condition until used. For in vitro experiments, DNC was diluted in complete culture medium as mentioned for each assay.

\section{Microculture tetrazolium (MTT) assay}

Microculture tetrazolium (MTT) assay was used to assess the inhibitory effect of DNC, free curcumin and dendrosome on viability of SW480 cells. For this purpose, seeded cells were plated in 96-well plates at density of 5000 cells/100 $\mu 1$ PRMI in each well and then, exposed with either control or varying concentrations of DNC, free curcumin and dendrosome $(0-30 \mu \mathrm{M})$ for 24,48 , and $72 \mathrm{~h}$. (In previous studies have been indicated that curcumin decreased the proliferation of human colorectal cancer cells with an inhibitory rate of near $100 \%$ after $30-40 \mu \mathrm{M}$ curcumin treatment as a result we used above mentioned concentrations in MTT test and low doses $\left(\leq \mathrm{IC}_{50}\right)$ of curcumin and DNC to minimize the effect of anti-proliferation on the inhibition of migration in next tests ). Thereafter, the control medium and the media were replaced by MTT solution $(0.5 \mathrm{mg} / \mathrm{ml})$ and after $3 \mathrm{~h}$, with DMSO and the color absorbance was read at wavelength of $570 \mathrm{~nm}$ in an ELISA reader (company). The percentage of viable cells was calculated as $(\%)=(\mathrm{OD}$ exp/ OD con $\times 100$, where OD exp and OD con are the optical densities of exposed and control cells, respectively (Mosmann, 1983). The 50\% lethal concentration $\left(\mathrm{IC}_{50}\right)$ values of DNC on SW480 cells at different time intervals were determined by GraphPad Prism 5 statistical package. The parameter $\mathrm{C}$ or $\mathrm{IC}_{50}$ was calculated according to the following equation: $\mathrm{Y}=\left[\mathrm{a}-\mathrm{d} / 1+\left(\mathrm{X}+\mathrm{c}^{\mathrm{b}}\right)\right]+\mathrm{d}$ (Sebaugh, 2011).

\section{Wound-healing assay}

Migration of SW480 cells was measured by woundhealing assay as described previously with some modifications. The cancer cells were cultured in 24-well plates and grown in RPMI 1640 containing 10\% FBS to nearly confluent cell monolayer, then a scratch wound was created on the cell surface using a micropipette tip. The monolayer was washed once with PBS to remove debris or the detached cells from the monolayer. Cells incubated at different concentrations $(0,3,6$ and $9 \mu \mathrm{M})$ of DNC, then the cultures were incubated at $37^{\circ} \mathrm{C}$, stained with $20 \%$ Giemsa solution (Sigma Chemical) and prepared for the light microscope, subsequently photographed with microscope at 0 and $24 \mathrm{~h}$, respectively. For each time point, four measurements per scratch were carried out. For quantification and statistical analysis, the individual scratch width (micrometer, mean and standard deviation) was measured using the Image $\mathbf{J}$ software. The cell wound closure rate was measured for $0,3,6$ and $9 \mu \mathrm{M}$ of 
$\mathrm{DNC}$ at $24 \mathrm{~h}$ post-treatment (the scratch width at $0 \mathrm{~h}$ was supposed to be $1 \mu \mathrm{m}$ ) and calculated according to the following equation: $\%$ wound closure $=($ scratch width in Oh-the remaining scratch width in $24 \mathrm{~h}$ )/scratch width in $0 \mathrm{~h} \times 100 \%$. The cell wound closure rate at $0 \mathrm{~h}$ in each group was treated as $0 \%$. The experiments were performed in triplicate (Liang et al., 2007).

\section{Transwell migration assay}

In transwell migration assay, transwell membranes (8 $\mu \mathrm{m}$ pore size, $6.5 \mathrm{~mm}$ diameter; Corning Costar Corporation, Cambridge,MA) were coated with fibronectin $(2.5 \mathrm{mg} / \mathrm{ml})$, which was diluted in serum-free RPMI medium. Then, 300,000 cells were trypsinized, washed, and kept suspended in a medium lacking FBS. Migrationinducing medium (with 10\% FBS) was added to the lower wells of the chambers, Upper wells were filled with serumfree medium and cells (300,000 cells per well), in some cases, they contained different concentrations of DNC $(0$, $3,6$, and $9 \mu \mathrm{mol} / \mathrm{L})$. Then, the chamber was placed into a humidified incubator. After $8 \mathrm{~h}$, assays were stopped by removal of the filters and medium from the upper wells. Filters were fixed with methanol by brief submersion and were subsequently wiped on the cells of the upper side using the Q-tip. Filters were stained with $20 \%$ Giemsa solution (Sigma Chemical) and prepared for the light microscope. Evaluation of completed transmigration was performed, random fields, scanned (four fields per filter) and the cells that migrated to the lower surface were also counted (Chen, 2005). The Metastasis Index was measured for $0,3,6$ and $9 \mu \mathrm{M}$ of DNC and calculated by the following equation:

Metastasis Index=Mean of Cells migrated to the lower surface / Mean of Cells migrated to the lower surface in 0 $\mu \mathrm{M}$ of DNC (Control). The Metastasis Index in $0 \mu \mathrm{M}$ of DNC was 1 . The experiments were performed in triplicate.

\section{Cell-matrix adhesion assay}

To measure the relative attachment of the SW480 cells to immobilized fibronectin, 96-well plates were coated with $100 \mu \mathrm{l}$ of $2.5 \mathrm{mg} / \mathrm{ml}$ fibronectin (Sigma, USA) and incubated overnight at $4^{\circ} \mathrm{C}$. Then, the plates blocked with $100 \mu 1 \mathrm{PBS}$ containing $3 \%(\mathrm{w} / \mathrm{v}) \mathrm{BSA}$ for $30 \mathrm{~min}$ at $37^{\circ} \mathrm{C}$. For measuring baseline nonspecific binding, other wells were coated with $1 \mathrm{mg} / \mathrm{ml} \mathrm{BSA}$. Following pretreatment of cells with $0,3,6$ and $9 \mu \mathrm{M}$ DNC for $24 \mathrm{~h}$, the cells were resuspended in serum-free RPMI1640 (SFM) and BSA $(1: 1)$ and incubated at $37^{\circ} \mathrm{C}$ for 90 min to allow recovery of cell surface receptors and alleviate the effect of trypsin on the cells. Approximately 50,000 cells in $100 \mu 1$ of SFM-BSA were seeded in quadruplicates into each fibronectin-coated well and incubated at $37^{\circ} \mathrm{C}$ for 90 min. Nonadherent cells were removed after washing with PBS, and the adherent cells were fixed in ethanol for 10 min. After $5 \mathrm{~min}$ of crystal violet staining $(0.1 \%(\mathrm{w} / \mathrm{v})$ in $25 \%(\mathrm{v} / \mathrm{v})$ methanol) at room temperature, the cells were gently rinsed five times with water to remove unbound stain and allowed to air-dry at room temperature. Fixed cells were lysed by $0.2 \%$ Triton $\mathrm{X}-100$, and the absorbance was measured at $550 \mathrm{~nm}$ as follows: \% Adhesion to matrix in $0 \mu \mathrm{M}$ of DNC as 100 (Dastpeyman et al., 2012).

\section{Analysis of gene expression by real-time PCR}

Following pretreatment of cells with 4,8 and $12 \mu \mathrm{M}$ DNC for $48 \mathrm{~h}$, total RNA was extracted from SW480 cells with Trizol (Invitrogen, Cergy-Pontoise, France) according to the manufacturer's instructions. The quantity and quality of the isolated RNA were determined by Nanodrop ND1000 (Nanodrop Technologies, Wilmington, Delaware, USA) and agarose gel electrophoresis (1\% agarose; Gibco/ BRL), respectively. The amount of the 260/280 OD ratio of all samples was between 1.8 and 2.2, indicating their high purity. cDNA was synthesized using a RevertAid Reverese transcriptase cDNA Synthesis Kit (Fermentas, Germany) according to the manufacturer's protocol and stored at $-20^{\circ} \mathrm{C}$ until use. Primers were designed onto two adjacent exons with a very long intron in middle by AlleleID 6.0 (http://www.premierbiosoft.com). All of the selected primers sequences were further analyzed with the Oligo software (http:// www.cambio.co.uk/index. php). Gapdh was used as an internal housekeeping control gene to normalize the mRNA expression levels. Realtime PCR was performed with a light cycler instrument (Applied Biosystems 7500, USA) using 5x HOT FIREPol ${ }^{\circledR}$ EvaGreen ${ }^{\circledR}$ HRM Mix (ROX) (Solis BioDyne Inc.). In a total volume of $10 \mu \mathrm{l}, 2 \mu \mathrm{l}$ eva Green master mix, $1 \mu \mathrm{l}$ of cDNA samples, $0.5 \mu \mathrm{l}$ of forward and reverse primers (10 pmol) and $6.5 \mu \mathrm{l}$ of nuclease-free water (Qiagen, Hilden, Germany) were added into each capillary tube. The PCR condition included an initial denaturation of $1 \mathrm{~min}$ at $95^{\circ} \mathrm{C}$ followed by 40 cycles at $95^{\circ} \mathrm{C}$ for $15 \mathrm{~s}$, at $62^{\circ} \mathrm{C}$ for $30 \mathrm{~s}$ and at $72^{\circ} \mathrm{C}$ for $30 \mathrm{~s}$. The specificity of the PCR products was assessed by verifying a single peak in melting curve analysis. For complementary length verification, PCR products were visualized on $1.5 \%$ agarose gel stained with ethidium bromide. No template controls were included in each run. Primer efficiencies were calculated by LinregePCR 12.17.1.0 and fold change in relative expression of each target mRNA calculated on the basis of comparative $\mathrm{Ct}\left(2^{-\Delta \Delta \mathrm{Ct}}\right)$ method. The sequences of primers are listed in Table 1.

\section{Statistical analysis}

The results were expressed as mean \pm SD. All experiments were performed in triplicate except for Transwell Migration Assay, which was performed in duplicate. Statistical significances of difference throughout this study were calculated using a Student's t-test and by

Table 1. Nucleotide Sequences of the Primers Used for Real-time RT-PCR

\begin{tabular}{lclcc}
\hline Gene & Accession number & \multicolumn{1}{c}{ Forward primer (5'-3') } & \multicolumn{1}{c}{ Reverse primer (5'-3') } & Size (bp) \\
\hline Gapdh & NM_002046.4 & GTGAACCATGAGAAGTATGACAAC & CATGAGTCCTTCCACGATACC & 123 \\
Hef 1 & NM_182966 & CTGGATGGATGACTACGATT & TCTGAGAGGGCTTCCACTTC & 203 \\
Zeb 1 & NM_001174094 & GCATACACCTACTCAACTAC & CACAAATCACAAGCATACAT & 203 \\
Claudin 1 & NM_021101 & ATGAGGTGCAGAAGATGAGG & GGTGTTGGGTAAGAGGTTGT & 256 \\
\hline
\end{tabular}


Mohammad Javad Dehghan Esmatabadi et al

one-way variance analysis. p values $<0.05$ were considered significant.

\section{Results}

Effect of DNC, free curcumin and dendrosome on cell viability of the SW480 cells

The inhibitory evaluation, which was carried out through MTT assay using various pharmacologically achievable concentrations (0-30 $\mu \mathrm{M})$ of DNC, free curcumin and dendrosome at different time intervals (24, 48 and $72 \mathrm{~h}$ ), demonstrated that DNC inhibits cell viability of SW480 cells in a dose and time dependent manner $(p<0.001)$. As shown in Figure 1(a, b, c), treatment of the cell lines with DNC at 3, 6, 9, 12, 15, 18, 21, 25 and 30 $\mu \mathrm{M}$ after $24 \mathrm{~h}$ reduced cell viability of SW480 cells by 7.5, $16.5(\mathrm{p}<0.001), 22.5(\mathrm{p}<0.01), 43(\mathrm{p}<0.001), 53(\mathrm{p}<0.001)$, $55.5(\mathrm{p}<0.001), 59.5(\mathrm{p}<0.01), 62.5(\mathrm{p}<0.01)$ and 71 $(\mathrm{p}<0.01) \%$, respectively. Compared with controls, the cell viability was not altered very much by DNC, except at the concentrations of 12-30 $\mu \mathrm{M}$. Therefore, it was confirmed that a 24-h treatment of DNC with a concentration

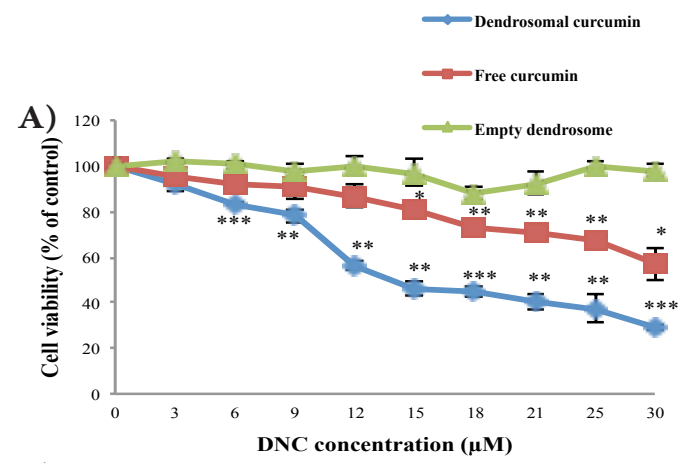

B
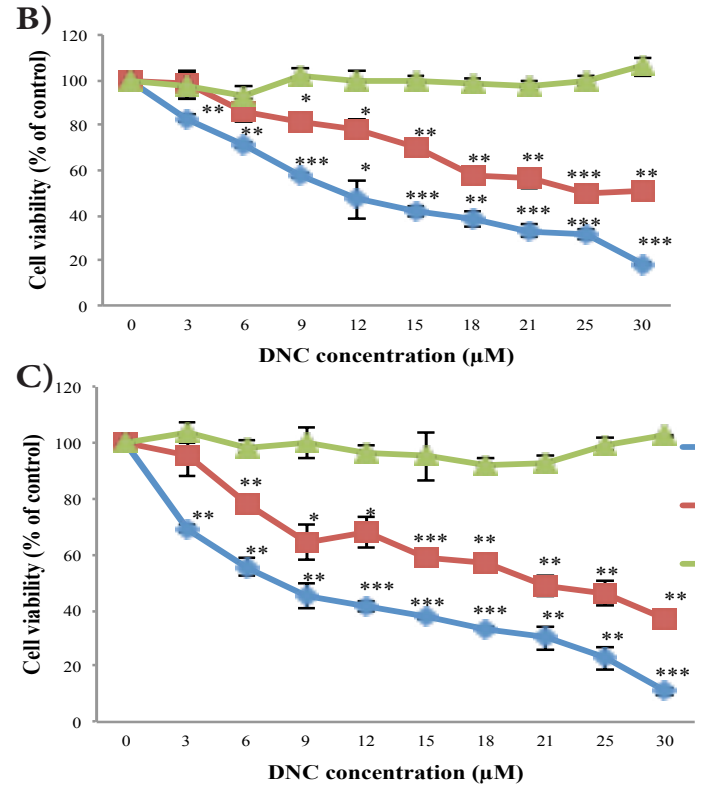

Figure 1. Effects of DNC, Free Curcumin and Dendrosome on SW480 Cell Viability. The cell line was treated with different concentrations of DNC, free curcumin and free dendrosome (0-30 $\mu \mathrm{M})$ for 24 (A) 48; (B) and 72h; (C) and their viability was assessed using MTT assay. Results are expressed as a percentage of viability compared to control and are presented as mean $\pm \mathrm{SD}$ from three independent experiments, Significance was set at $* \mathrm{p}=0.05 ; * * \mathrm{p}=0.01 ; * * \mathrm{p}=0.001$ ranging from 0 to $9 \mu \mathrm{M}$, has no high cytotoxic effect on the metastatic SW480 cells. Thus, this concentration range was used in the subsequent experiments. DNC had the ability to inhibit SW480 cells with $\mathrm{IC}_{50}$ in the range of about $15.86,11.57$ and $7.64 \mu \mathrm{M}$ at 24,48 and $72 \mathrm{~h}$. However, the viability of SW480 cells was not affected by free curcumin only at 48 and $72 \mathrm{~h}$ (from 9-30 $\mu \mathrm{M}$ ). On the other hand, no inhibitory effect was observed for dendrosome alone. In total, these findings demonstrate that dendrosome increased the water solubility and entry of curcumin to cells without any toxic effects correlated with dendrosomes as a carrier.

\section{DNC inhibits migration of SW480 cells}

SW480 is a metastatic cancer cell line both in vitro and in vivo (Yu et al., 2013). Due to the fact that DNC could reduce cell viability as the concentrations of DNC over $12 \mu \mathrm{M}$ at $24 \mathrm{~h}$ (the $\mathrm{IC}_{50}$ is $15.86 \mu \mathrm{M}$ ), the effects of DNC on migration ability of SW480 cells were performed at the concentration range below $12 \mu \mathrm{M}$ and determined by the wound-healing assay and the Transwell migration assay. Concentration dependently, DNC (3-9 $\mu \mathrm{M})$ was able to significantly inhibit SW480 cancer cell migration, and this effect was consistent across both the wound-healing and

A)

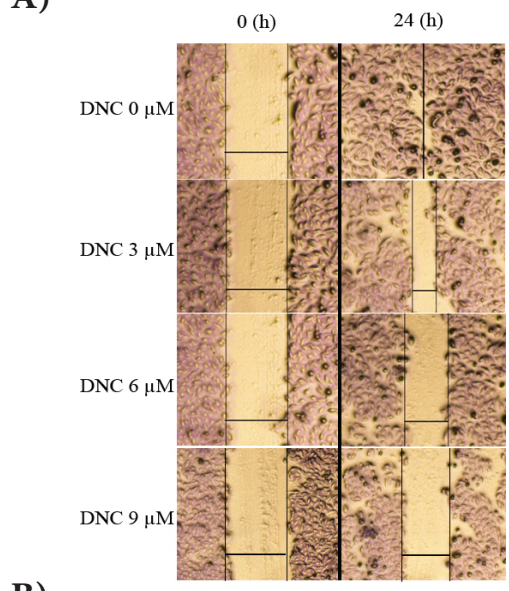

B)

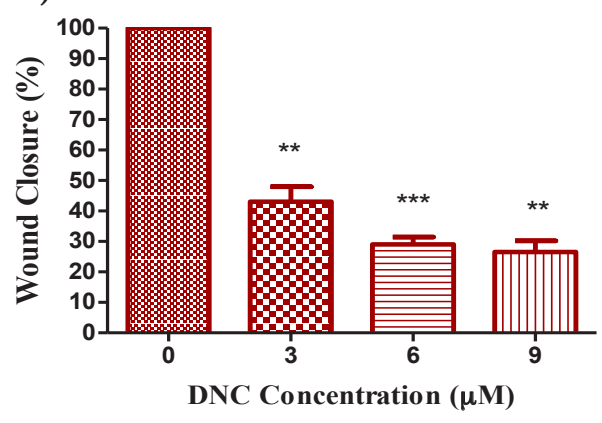

Figure 2. Effects of DNC on Cell Migration of SW480 Cells. Wound-healing assay showed the inhibitory effects of DNC on SW480 cell migration (A). Confluent monolayers of SW480 cells were scarred and stained with $20 \%$ Giemsa solution and repair was monitored microscopically after $24 \mathrm{~h}$ of treatment with DNC (3-9 $\mu \mathrm{M}))$ Data shown are from a single experiment; (B). For quantification analysis, the individual scratch width (micrometer) was measured using the Image $\mathbf{J}$ software and the wound closure rate was calculated. Data are presented as mean \pm SD from three independent experiments, Significance was set at $* \mathrm{p}=0.05 ; * * \mathrm{p}=0.01 ; * * \mathrm{p}=0.001$ 


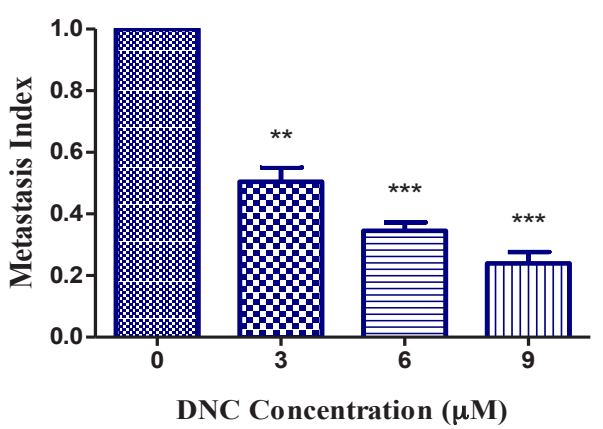

Figure 3. Effects of Curcumin on Cell Migration of SW480 Cells. The Transwell migration assay showed the inhibitory effects of DNC on SW480 cells migration. After 8h of incubation with the indicated concentration of DNC, cells that migrate to the lower chamber were fixed, stained with $20 \%$ Giemsa solution and photographed with microscope. For measuring the Metastasis Index, Random fields were scanned (four fields per filter of the well) for the presence of cells on the lower side of the membrane. Data are presented as mean $\pm \mathrm{SD}$ from three independent experiments, Significance was set at ${ }^{*} \mathrm{p}=0.05 ; * * \mathrm{p}=0.01 ; * * * \mathrm{p}=0.001$

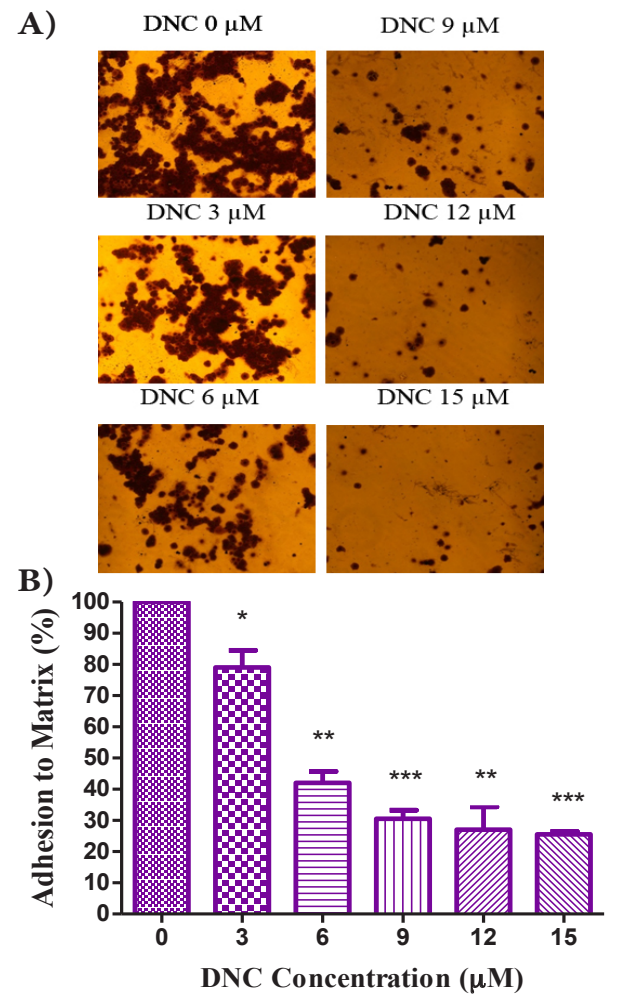

Figure 4. Effects of DNC on Cell Adhesion of SW480 Cells. (A). After pretreatment of the cells with DNC concentrations of $3,6,9,12$ and $15 \mu \mathrm{M}$ for $24 \mathrm{~h}$, cells were harvested and used for adhesion assay. Approximately 50,000 cells in $100 \mu \mathrm{l}$ of SFM-BSA were seeded in quadruplicates into each fibronectin-coated well and incubated at $37^{\circ} \mathrm{C}$ for 90 min. Nonadherent cells were removed by washing with PBS twice and the adherent cells were fixed. After crystal violet staining, adherent cells were photographed with microscope) Data shown are from a single experiment; (B).For quantification analysis, the cellular absorbance was measured compared to the control at $550 \mathrm{~nm}$. Data are presented as mean $\pm \mathrm{SD}$ from three independent experiments, Significance was set at $* \mathrm{p}=0.05$; $* * \mathrm{p}=0.01 ; * * * \mathrm{p}=0.001$

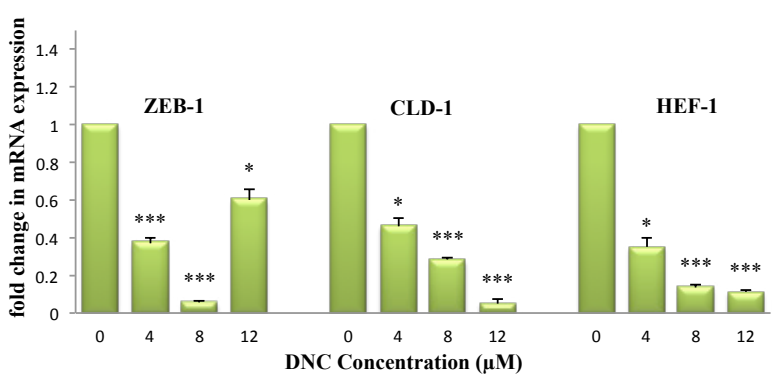

Figure 5. Effect of DNC on Transcriptional Levels of the Genes (Zeb 1, Claudin 1, Hef 1) Measured by Real-time PCR. Data are shown as fold change in relative expression compared with Gapdh on the basis of Comparative $\mathrm{Ct}(2-\Delta(\Delta \mathrm{Ct}))$ method. Data are presented as mean $\pm \mathrm{SD}$ from three independent experiments, Significance was set at * $\mathrm{p}=0.05$; $* * \mathrm{p}=0.01 ; * * \mathrm{p}=0.001$

transwell migration assays (Figure 2 and 3). Compared to the controls, different concentrations of DNC (3, 6 and $9 \mu \mathrm{M})$ reduced $\%$ wound closure and Metastasis Index of SW480 cells by $57 \%(\mathrm{p}<0.01)-0.495(\mathrm{p}<0.01), 71 \%$ $(\mathrm{p}<0.001)-0.645(\mathrm{p}<0.001)$ and $73.5 \%(\mathrm{p}<0.01)-0.76$ $(\mathrm{p}<0.001)$, respectively.

\section{DNC inhibits adhesion of the SW480 cells to matrix}

Evaluation of DNC's effect on SW480 attachment was done using fibronectin. Compared to the controls, different concentrations of DNC $(3,6,9,12$ and $15 \mu \mathrm{M})$ after $24 \mathrm{~h}$ reduced adhesion of SW480 cells to matrix by $21 \%$ $(\mathrm{p}<0.05), 58 \%(\mathrm{p}<0.01), 69.5(\mathrm{p}<0.001), 73(\mathrm{p}<0.01)$ and $74.5(\mathrm{p}<0.001) \%$, respectively. The results showed that DNC markedly reduced the cells attachment to fibronectin in a dose dependent- manner (Figure 4).

\section{DNC decreases the mRNA levels of Hef 1, Zeb 1 and Claudin 1}

Comparing with the controls, DNC concentrations of 4,8 and $12 \mu \mathrm{M}$ caused a significant reduction in mRNA level of Claudin 1 and Hef 1 by a fold change of 0.46 $(\mathrm{p}<0.05), 0.34(\mathrm{p}<0.05)$ in $4 \mu \mathrm{M}, 0.28(\mathrm{p}<0.001), 0.13$ $(\mathrm{p}<0.001)$ in $8 \mu \mathrm{M}$ and $0.03(\mathrm{p}<0.001), 0.11(\mathrm{p}<0.001)$ in $12 \mu \mathrm{M}$ compared to the control, respectively. It also significantly reduced the mRNA level of Zeb 1, by a fold change of $0.37(\mathrm{p}<0.001), 0.056(\mathrm{p}<0.001)$ and $0.57(\mathrm{p}<0.05)$, at the concentrations of 4,8 and $12 \mu \mathrm{M}$ compared to the control, respectively, (Figure 5). Data are shown as fold change in relative expression compared with Gapdh on the basis of Comparative $\mathrm{Ct}\left(2^{-\Delta(\Delta \mathrm{Ct})}\right)$ method.

\section{Discussion}

In spite of the clinical and technical progresses in malignant colorectal cancer therapy, the rate of mortality due to delayed diagnosis and occurrence of metastasis and invasiveness of the tumor has not changed remarkably. Most of the drugs available for treatment of colorectal cancer are not appropriate for their high cost, toxicity and not guaranteeing against metastasis and cancer recurrence (Kimelman and Xu, 2006; Huei, 2008; Das et al., 2010; Babaei et al., 2012). In view of these facts, the need for a 
more efficient treatment for cases affected with metastatic colorectal cancers which make up the majority of patients cannot be disregarded. The pleiotropic characteristics of curcumin to affect multiple signaling pathways make it an attractive compound for cancer therapy. At present, the growing knowledge of nanotechnology promises to be helpful in the development of localized delivery of therapeutic agents by means of nanocarriers with small particle size. The anticancer properties of dendrosomal curcumin (DNC) as a new formulation of curcumin and dendrosome nanoparticle have been explored in mice models of fibrosarcoma and different cancers, and toxicological analysis indicated that did not cause any severe side effects (Sarbolouki et al., 2000; Sadeghizadeh et al., 2008; Alizadeh et al., 2012; Babaei et al., 2012). Dendrosome improves the solubility of curcumin and facilitates its uptake by cancer cells, suggesting that this polymer could open new windows to successful drug delivery in cancer therapy (Alizadeh et al., 2012; Babaei et al., 2012). In this study, given the well-known limitations of malignant colorectal cancer treatment strategies, the role of DNC on the cell metastasis and mechanisms involved in this process in SW480 cells-a highly tumorigenic and invasive colon carcinoma cell line (Trainer et al., 1988) with increased expression of genes Zeb 1, Claudin 1, Hef 1 and matrix-metalloproteinases (MMP)-1,-2,-3,-7 and -9 (Nobutomo et al., 2001; Meiko et al., 2002; Hlubek et al., 2004; Murray, 2004; Karadag et al., 2005; Tian et al., 2009; Qin et al., 2010; Amar et al., 2011; Li et al., 2011; Seo and Kim, 2011; Sanchez-Tillo et al., 2013; Wang et al., 2013; Zhao et al., 2013) and hyperactive WNT and Hedgehog signaling pathways (Korinek, 1997; Qualtrough et al., 2004), was evaluated. During carcinoma progression, cancer cells enhance their migratory and invasive capacity through down-regulation of epithelial markers, chiefly the inhibition of E-cadherin and the acquisition of a motile dedifferentiated phenotype as part of the epithelial-to mesenchymal transition. At the transcriptional level, E-cadherin is repressed by factor of the Zeb1 as final downstream effector (Schmalhofer et al., 2009; Brabletz and Brabletz, 2010; Gemmill et al., 2011; Sanchez-Tillo et al., 2011). Over the last few years, a wealth of reports has linked Zeb1 expression to increased aggressiveness capacity in a wide range of primary human carcinomas (Graham et al., 2008; Adachi et al., 2009; Schmalhofer et al., 2009; Sanchez-Tillo et al., 2013). Hef1, also known as NEDD9, is a multi-domain scaffolding protein of the Cas family, that localizes to focal adhesions to coordinate FAK and Src signaling cascades in integrin-dependent adhesion and migration. High levels of Hef1 have been reported in various human cancers including melanoma, lung cancer and colon cancer (Kim et al., 2006; Ji et al., 2007; Izumchenko et al., 2009; Li et al., 2011). Tight junctions play a major role in establishment and maintenance of cell polarity, differentiation, and controlling cell motility and invasiveness. Over-expression of Claudins, the main molecules of tight junction's transmembrane, particularly Claudin 1 was observed to increase metastasis in different human cancers (Gupta and Ryan, 2010). Several studies have analyzed the role of Zeb1, Hef1 and Claudin 1 in cellular adhesion as well as in cancer development and metastasis. Overexpression of Zeb1, Hef1 and claudin 1 has been implicated in promotion of cell migration and metastasis in various types of cancers. Vice versa, a knockdown of Zeb1, Hef1 and Claudin 1 factors with siRNA or shRNA in undifferentiated cancer cells such as SW480 cells resulted in metastasis inhibition (Sarah et al., 2002; Leu et al., 2003; Ray et al., 2003; Conroy et al., 2005; Natarajan et al., 2006; Sita et al., 2006; Spaderna et al., 2006; Su, 2006a; Aigner et al., 2007; Ji et al., 2007; Izumchenko et al., 2009; Wellner et al., 2009; Myal et al., 2010; Amar et al., 2011; Li et al., 2011; Chen et al., 2012; Sanchez-Tillo et al., 2013). To date, few studies have investigated the molecular mechanisms through which curcumin inhibits metastasis: Amitava Chatterjee et al. suggested that curcumin impedes cell metastasis by inhibiting the expression of cell adhesions molecules such as integrin receptors, focal adhesion kinase (FAK) and enhances the expression of E-cadherin (Ray et al., 2003). Tzeng-Horng Leu et al. indicated that curcumin can retard cellular migration via downregulation of Src and FAK kinase activity, two important players in integrin signal transduction (Leu et al., 2003). And finally, our results in agreement with previous reports (Bharat et al., 2005; Sita et al., 2006; Su, 2006a; Xiaofu et al., 2006; Hong, 2008; Huei, 2008; Jeffery et al., 2009; Xin, 2009; Li et al., 2011), revealed that DNC significantly decreases migration and adhesion ability of SW480 cells through the inhibition of Claudin 1, Zeb1 and Hef1 mRNAs expression, suggesting that DNC exerted its effects partly through regulating the expression of cell adhesion molecules in SW480 cells. There are evidences demonstrating that disregulation of TGFb, RTK/Ras, Notch, Hedgehog and WNT dependent signaling pathways are the major causes for the occurrence of metastasis (Huber et al., 2005). Some studies had previously indicated that curcumin blocks WNT pathway in different colon cancer cell lines, particularly in SW480, and since WNT pathway is one of the main regulators of expression of these genes (Nobutomo et al., 2001; Amar et al., 2011; Li et al., 2011), the lowered expression in the studied genes partly may be attributed to WNT inhibition by curcumin. Moreover curcumin was shown to inhibit EGFR (Lev, 2004), HDAC and NFKB pathways in colon cancer cell lines (Su, 2006b; Bora-Tatar, 2009) through which Claudin 1 and Zeb1 is somehow regulated, therefore Claudin 1 and Zeb1 declined expression may also be related to the blockage of these pathways.

In conclusion, in a nut shell, the results of this study showed that an herbal nano-particle, commercially known as dendrosomal curcumin, could exert its anticancer effects such as inhibition of cellular growth, invasiveness and adhesion of SW480 colon cancer cells through reducing the expression of Hef 1 , Zeb 1 and Claudin 1 genes. This new herbal nanodrug could not only suppress the proliferation of colorectal cancer cells but also inhibit metastasis-associated events and thus might be considered as a safe formulation for therapeutic purpose in colorectal cancer cases.

\section{Acknowledgements}

Authors wish to thank Dr. Roohollah Nakhaei Sistani 
for his help to accomplish this study. This work was financially supported by Department of Genetics, Faculty of Biological Sciences, Tarbiat Modares University.

\section{References}

Adachi Y, Takeuchi T, Nagayama T, et al (2009).Zeb1-mediated $\mathrm{T}$-cadherin repression increases the invasive potential of gallbladder cancer. FEBS Lett, 583, 430-6.

Aggarwal S, Ichikawa H, Takada Y, et al (2006). Curcumin (diferuloylmethane) down-regulates expression of cell proliferation and antiapoptotic and metastatic gene products through suppression of IkappaBalpha kinase and Akt activation. Mol Pharmacol, 69, 195-206.

Aigner K, Dampier B, Descovich L, et al (2007). The transcription factor ZEB1 (deltaEF1) promotes tumour cell dedifferentiation by repressing master regulators of epithelial polarity. Oncogene, 26, 6979-88.

Alizadeh AM, Khaniki M, Azizian S, et al (2012). Chemoprevention of azoxymethane-initiated colon cancer in rat by using a novel polymeric nanocarrier-curcumin. Eur J Pharmacol, 689, 226-32.

Amar S, Ashok S, Punita D (2011). Claudin-1 Up-regulates the repressor ZEB-1 to inhibit ecadherin expression in colon cancer cells. Gastroenterology, 141, 2140-53.

Ammon HP, Wahl MA (1991). Pharmacology of curcuma longa. Planta Med, 57, 1-7.

Anand P, Kunnumakkara AB, Newman RA, et al (2007). Bioavailability of curcumin: problems and promises. $\mathrm{Mol}$ Pharm, 4, 807-18.

Anand P, Thomas SG, Kunnumakkara AB (2008). Biological activities of curcumin and its analogues (Congeners) made by man and mother nature. Biochem Pharmacol, 76, 1590611.

Babaei E, Sadeghizadeh M, Hassan ZM, et al (2012). Dendrosomal curcumin significantly suppresses cancer cell proliferation in vitro and in vivo. Intern Immunopharmacol, 12, 226-34.

Bharat BA, Shishir S, Yasunari T, et al (2005). Curcumin suppresses the paclitaxel-induced nuclear factor metastasis of human breast cancer in nude mice kb pathway in breast cancer cells and inhibits lung. Clin Cancer Res, 11, 7490-8.

Bora-Tatar G, Dayangac-Erden D, Demir AS, et al (2009). Molecular modifications on carboxylic acid derivatives as potent histone deacetylase inhibitors: Activity and docking studies. Bioorg Med Chem, 17, 5219-28.

Brabletz S, Brabletz T (2010). The ZEB/miR-200 feedback loop-a motor of cellular plasticity in development and cancer? EMBO Rep , 11, 670-7.

Chen HC (2005). Boyden chamber assay. Methods Mol Biol, 294, 15-22.

Chen ML, Liang LS, Wang XK (2012). miR-200c inhibits invasion and migration in human colon cancer cells SW480/620 by targeting ZEB1. Clin Exp Metastasis, 29, 457-69.

Conroy T, Paillot B, Francois E, et al (2005). Irinotecan plus oxaliplatin and leucovorin-modulated fluorouracil in advanced pancreatic cancer-a groupe tumeurs digestives of the federation nationale des centres de lutte contre le cancer study. J Clin Oncol, 23, 1228-36.

Das T, Sa G, Saha B, et al (2010). Multifocal signal modulation therapy of cancer: ancient weapon, modern targets. Mol Cell Biochem, 336, 85-95.

Dastpeyman M, Motamed N, Azadmanesh K, et al (2012). Inhibition of silibinin on migration and adhesion capacity of human highly metastatic breast cancer cell line, MDAMB-231, by evaluation of beta1-integrin and downstream molecules, Cdc42, Raf-1 and D4GDI. Med Oncol, 29, 2512-8.

Ferlay J, Shin HR, Bray F, et al (2010). GLOBOCAN 2008 v2.0, Cancer incidence and mortality worldwide: IARC cancerbase No. 10 [Internet]. Lyon, France.

Ferrari E, Pignedoli F, Imbriano C (2011). Newly synthesized curcumin derivatives: crosstalk between chemico-physical properties and biological activity. J Med Chem, 54, 8066-77.

Gemmill RM, Roche J, Potiron VA, et al (2011). ZEB1responsive genes in non-small cell lung cancer. Cancer Lett, 300, 66-78.

Gou M, Men K, Shi H, et al (2011). Curcumin-loaded biodegradable polymeric micelles for colon cancer therapy in vitro and in vivo. Nanoscale, 3, 1558-67.

Graham TR, Zhau HE, Odero-Marah VA, et al (2008). Insulinlike growth factor-I-dependent up-regulation of ZEB1 drives epithelial-to-mesenchymal transition in human prostate cancer cells. Cancer Res, 68, 2479-88.

Gulhati P, Bowen KA, Liu J, et al (2011). mTORC1 and mTORC2 regulate EMT, motility, and metastasis of colorectal cancer via RhoA and Rac1 signaling pathways. Cancer Res, 71, 3246-56.

Gupta IR, Ryan AK (2010). Claudins: unlocking the code to tight junction function during embryogenesis and in disease. Clin Genet, 77, 314-25.

Hlubek F, Spaderna S, Jung A, et al (2004). Beta-catenin activates a coordinated expression of the proinvasive factors laminin-5 gamma2 chain and MT1-MMP in colorectal carcinomas. Int J Cancer, 108, 321-6.

Hong IK (2008). Curcumin inhibition of integrin (a6b4)dependent breast cancer cell motility and invasion. Cancer Prev Res, 1, 385-91.

Hong JH, Ahn KS, Bae E, et al (2006). The effects of curcumin on the invasiveness of prostate cancer in vitro and in vivo. Prostate Cancer Prostatic Dis, 9, 147-52.

Huber MA, Kraut N, Beug H (2005). Molecular requirements for epithelial-mesenchymal transition during tumor progression. Curr Opin Cell Biol, 17, 548-58.

Huei WC (2008). Curcumin inhibits lung cancer cell invasion and metastasis through the tumor suppressor HLJ1. Cancer Res, 68, 7428-38.

Hynes RO (2002). Integrins: bidirectional, allosteric signaling machines. Cell, 110, 673-87.

Izumchenko E, Singh MK, Plotnikova OV, et al (2009). NEDD9 promotes oncogenic signaling in mammary tumor development. Cancer Res, 69, 7198-206.

Jeffery GH, Henry LS, Charles ER (2009). Curcumin blocks CCL2 induced adhesion, motility and invasion, in part, through down-regulation of CCL2 expression and proteolytic activity. Int J Oncol, 34, 1319-27.

Ji H, Ramsey MR, Hayes DN, et al (2007). LKB1 modulates lung cancer differentiation and metastasis. Nature, 448, 807-10.

Karadag A, Fedarko NS, Fisher LW (2005). Dentin matrix protein 1 enhances invasion potential of colon cancer cells by bridging matrix metalloproteinase-9 to integrins and CD44. Cancer Res, 65, 11545-52.

Khor TO, Keum YS, Lin W, et al (2006). Combined inhibitory effects of curcumin and phenethyl isothiocyanate on the growth of human PC-3 prostate xenografts in immunodeficient mice. Cancer Res, 66, 613-21.

Kim M, Gans JD, Nogueira C, et al (2006). Comparative oncogenomics identifies NEDD9 as a melanoma metastasis gene. Cell, 125, 1269-81.

Kimelman D, Xu W (2006). beta-catenin destruction complex: insights and questions from a structural perspective. Oncogene, 25, 7482-91.

Korinek V (1997). Constitutive transcriptional activation by a 
beta -catenin-Tcf complex in APC-/- colon carcinoma. Sci, 275, 1784-7.

Ku G, Tan IB, Yau T, et al (2012). Management of colon cancer: resource-stratified guidelines from the Asian oncology summit 2012. Lancet Oncol, 13, 470-81.

Kuo ML, Huang TS, Lin JK (1996). Curcumin, an antioxidant and anti-tumor promoter, induces apoptosis in human leukemia cells. Biochim Biophys Acta, 1317, 95-100.

Kushwaha S, Rastogl A, Rai A, et al (2012). Novel drug delivery system for anticancer drug: a review. Intern J Pharm Tech Res, 4, 542-53.

Leu TH, Su SL, Chuang YC, et al (2003). Direct inhibitory effect of curcumin on Src and focal adhesion kinase activity. Biochem Pharmacol, 66, 2323-31.

Lev AA (2004). Inhibition of pancreatic and lung adenocarcinoma cell survival by curcumin is associated with increased apoptosis, downregulation of COX-2 and EGFR and inhibition of Erk1/2 activity. Anticancer Res, 26, 4423-30.

Li Y, Bavarva JH, Wang Z, et al (2011). HEF1, a novel target of Wnt signaling, promotes colonic cell migration and cancer progression. Oncogene, 30, 2633-43.

Liang CC, Park AY, Guan JL (2007). In vitro scratch assay: a convenient and inexpensive method for analysis of cell migration in vitro. Nat Protoc, 2, 329-33.

Meiko T, Tatsuhiko T, Motoharu S, et al (2002). Identification of membrane-type matrix metalloproteinase- 1 as a target of the b-catenin/Tcf4 complex in human colorectal cancers. Oncogene, 21, 5861-7.

Meng W, Takeichi M (2009). Adherens junction: molecular architecture and regulation. Cold Spring Harb Perspect Biol, 1, 289-91.

Mirgani MT, Isacchi B, Sadeghizadeh M, et al (2014). Dendrosomal curcumin nanoformulation downregulates pluripotency genes via miR-145 activation in U87MG glioblastoma cells. Int J Nanomedicine, 9, 403-17.

Mosmann T (1983). Rapid colorimetric assay for cellular growth and survival: application to proliferation and cytotoxicity assays. J Immunol Methods, 65, 55-63.

Murray DW (2004). Molecular mechanisms of human colorectal cancer metastasis: identification of novel biomarkers. $\mathrm{PhD}$ thesis, Dublin City Univers, 7, 4968-3.

Myal Y, Leygue E, Blanchard AA (2010). Claudin 1 in breast tumorigenesis: revelation of a possible novel "claudin high" subset of breast cancers. J Biomed Biotechnol, 2010, 9568-97.

Natarajan M, Stewart JE, Golemis EA, et al (2006). HEF1 is a necessary and specific downstream effector of FAK that promotes the migration of glioblastoma cells. Oncogene, 25, 1721-32.

Nobutomo M, Mikio F, Shoichiro T, et al (2001). Involvement of claudin- 1 in the-catenin/Tcf signaling pathway and its frequent upregulation in human colorectal cancers. Oncol Res, 12, 469-76.

Orr WS, Denbo JW, Saab KR (2012). Liposome-encapsulated curcumin suppresses neuroblastoma growth through nuclear factor-kappa B inhibition. Surgery, 151, 736-44.

Paleos C (2013). Formation of artificial multicompartment vesosome and dendrosome as prospected drug and gene delivery carriers. J Control Release, 170, 141-52.

Qin Ly, Li Mn, Ren Wj, et al (2010). Silencing Pin1 suppresses the expression and bioactivity of MMP-9 through NF- $x \mathrm{~B}$ in colorectal carcinoma SW480 cells. Clin Oncol Cancer Res, 7, 12-7.

Qualtrough D, Buda A, Gaffield W, et al (2004). Hedgehog signalling in colorectal tumour cells: induction of apoptosis with cyclopamine treatment. Int J Cancer, 110, 831-7.

Ravindran J, Prasad S, Aggarwal B (2009). Curcumin and cancer cells: how many ways can curry kill tumor cells selectively? Am Assoc Pharmaceutical Scientists, 11, 495-510.

Ray S, Chattopadhyay N, Mitra A, et al (2003). Curcumin exhibits antimetastatic properties by modulating integrin receptors, collagenase activity, and expression of $\mathrm{Nm} 23$ and E-cadherin. J Environ Pathol Toxicol Oncol, 22, 49-58.

Sadeghizadeh M, Ranjbar B, Damaghi M (2008). Dendrosomes as novel gene porters-III. J Chem Technol Biotechnol, 83, 912-20.

Sanchez-Tillo E, de Barrios O, Siles L, et al (2013). ZEB1 Promotes invasiveness of colorectal carcinoma cells through the opposing regulation of UPA and PAI-1. Clin Cancer Res, 19, 1071-82.

Sanchez-Tillo E, Siles L, de Barrios O, et al (2011). Expanding roles of ZEB factors in tumorigenesis and tumor progression. Am J Cancer Res, 1, 897-912.

Sarah JF, Margret BE, Geraldine MON, et al (2002). Dissection of HEF1-dependent functions in motility and transcriptional regulation. J Cell Sci, 115, 99-111.

Sarbolouki MN, Sadeghizadeh M, Yaghoobi MM, et al (2000). Dendrosomes: a novel family of vehicles for transfection and therapy. J Chem Technol Biotechnol, 75, 919-22.

Schmalhofer O, Brabletz S, Brabletz T (2009). E-cadherin, beta-catenin, and ZEB1 in malignant progression of cancer. Cancer Metastasis Rev, 28, 151-66.

Sebaugh JL (2011). Guidelines for accurate EC50/IC ${ }_{50}$ estimation. Pharm Stat, 10, 128-34.

Seo EY, Kim WK (2011). Red ginseng extract reduced metastasis of colon cancer cells in vitro and in vivo.J Ginseng Res, 35, 315-24.

Sita A, Haruyo I, Yasunari T, et al (2006). Curcumin (diferuloylmethane) down-regulates expression of cell proliferation and antiapoptotic and metastatic gene products through suppression of kinase and akt activation. Mol Pharmacol, 69, 195-206.

Spaderna S, Schmalhofer O, Hlubek F, et al (2006). A transient, EMT-linked loss of basement membranes indicates metastasis and poor survival in colorectal cancer. Gastroenterology, 131, 830-40.

Sporn MB (1997). The War on Cancer: A Review. Ann New York Academy Scie, 833, 137-46.

Su CC, Chen, GW, Lin, JG, Wu, LT, Chung, JG (2006a). Curcumin inhibits cell migration of human colon cancer colo 205 cells through the inhibition of nuclear factor kappa B/p65 and down-regulates cyclooxygenase-2 and matrix metalloproteinase-2 expressions. Anticancer Res, 26, 1281-8.

Su CC, Lin, JK (2006b). Curcumin-induced apoptosis of human colon cancer Colo 205 cells through the production of ROS, $\mathrm{Ca} 2+$ and the activation of caspase-3. Anticancer Res, 26, 4379-89.

Tian X, Du H, Fu X, et al (2009). Smad4 restoration leads to a suppression of $\mathrm{Wnt} /$ beta-catenin signaling activity and migration capacity in human colon carcinoma cells. Biochem Biophys Res Commun, 380, 478-83.

Trainer DL, Kline T, McCabe FL, et al (1988). Biological characterization and oncogene expression in human colorectal carcinoma cell lines. Int J Cancer, 41, 287-96.

Wang G, Wang F, Ding W, et al (2013). APRIL induces tumorigenesis and metastasis of colorectal cancer cells via activation of the PI3K/Akt pathway. PLoS One, 8, 552-98.

Wellner U, Schubert J, Burk UC, et al (2009). The EMT-activator ZEB1 promotes tumorigenicity by repressing stemnessinhibiting microRNAs. Nat Cell Biol, 11, 1487-95.

Xia Y-Q, Wei1, X-Y, et al (2014). Curcumin analogue A501 induces G2/M arrest and apoptosis in non-small cell lung cancer cells. Asian Pac J Cancer Prev, 15, 6893-8. 
Xiaofu W, Qingding W, Kirk LI, et al (2006). Curcumin inhibits neurotensin-mediated interleukin-8 production and migration of HCT116 human colon cancer cells. Clin Cancer Res, 12, 5346-55.

Xin ZC (2009). Curcumin suppresses proliferation and invasion in human gastric cancer cells by downregulation of PAK1 activity and cyclin D1 expression. Cancer Biol Therapy, 8, 1360-8.

Yu W, Xu YC, Tao Y, et al (2013). DcR3 regulates the growth and metastatic potential of SW480 colon cancer cells. Oncol Rep, 30, 2741-8.

Zhang Z-Y, Dong J-H, Chen Y-W, et al (2012). Galectin-9 acts as a prognostic factor with antimetastatic potential in hepatocellular carcinoma. Asian Pac J Cancer Prev, 13, 2503-9.

Zhao H, Huang A, Li P, et al (2013). E2A suppresses invasion and migration by targeting YAP in colorectal cancer cells. J Transl Med, 11, 317 . 